\title{
Cardiovascular epidemiology in the Asia-Pacific region
}

\begin{abstract}
By 2020, non-communicable diseases including cardiovascular diseases (CVD) are expected to account for seven out of every 10 deaths in the developing countries compared with less than half this value today. As a proportion of total deaths from all-causes, CVD in the Asiai Pacific region ranges from less than $20 \%$ in countries such as Thailand, Philippines and Indonesia to $201030 \%$ in urban China, Hong Kong, Japan, Korea and Malaysia. Countries such as New Zealand, Australia and Singapore have relatively high rates that exceed 30ї $35 \%$. The latter countries also rank high for coronary heart disease (CHD) mortality rate (more than 150 deaths per 100 000). In contrast, death from cerebrovascular disease is higher among East Asian countries including Japan, China and Taiwan (more than 100 per 100 000). It is worth noting that a number of countries in the region with high proportions of deaths from CVD have undergone marked declining rates in recent decades. For example, in Australia, between 1986 and 1996, mortality from CHD in men and women aged 30 ï 69 years declined by 46 and 51\%, respectively. In Japan, stroke mortality dropped from a high level of 150 per 100000 during the 1920sï 1940s to the present level of approximately 100 per 100 000. Nonetheless, CVD mortality rate is reportedly on the rise in several countries in the region, including urban China, Malaysia, Korea and Taiwan. In China, CVD mortality increased as a proportion of total deaths from $12.8 \%$ in 1957 to $35.8 \%$ in 1990 . The region is undergoing a rapid pace of urbanization, industrialization and major technological and lifestyle changes. Thus, monitoring the impact of these changes on cardiovascular risks is essential to enable the implementation of appropriate strategies towards countering the rise of CVD mortality.
\end{abstract}

Keyword: Asia-Pacific region; Cardiovascular disease mortality rates and trends 